and regulations related to dolphin protection resulted in the rapid shift of much of the fishing to the western Pacific and processing to American Samoa, Thailand and Puerto Rico. Between 1980 and 1985, the value of tropical tuna landings in California dropped tenfold, to $\$ 35$ million annually.

Since the early 1980 s, the nontuna fisheries have intensified and their value has doubled in real dollars. Much of this growth has been spurred by demand from the Pacific Rim for species such as sea urchin (see sidebar, right), herring, sablefish and other bottomfish. Important fisheries such as salmon, abalone, white seabass and some rockfishes have suffered serious declines. Loss of habitat (rivers and estuaries), poor water quality and overfishing are most often cited as reasons for the declines in abundance.

Marine recreational fishing is economically significant. California marine anglers annually land about 30 million fish and spend about $\$ 750$ million. Some species such as striped bass, sturgeon and abalone in Northern California are allocated solely for recreation.

\section{Fisheries management}

How are wild fish and shellfish populations managed? Two primary issues must be addressed. The first is to determine how many fish can be safely harvested each year and still sustain the population through reproduction and growth. The second challenge of the fish manager is to allocate the harvest among user groups such as commercial, recreational and Native American fishers. This also includes allocating some of the resource as forage for other fish, birds and marine mammals. Both issues are difficult and are a focus of much research and debate.

To determine what the sustainable rate of harvest could be requires estimates of the population size as well as variables such as growth rates, natural and fishing mortality rates, reproductive success and the effects of changes in the ocean environment on these variables. The unpredictable variability in ocean conditions and rapid

continued on p. 32

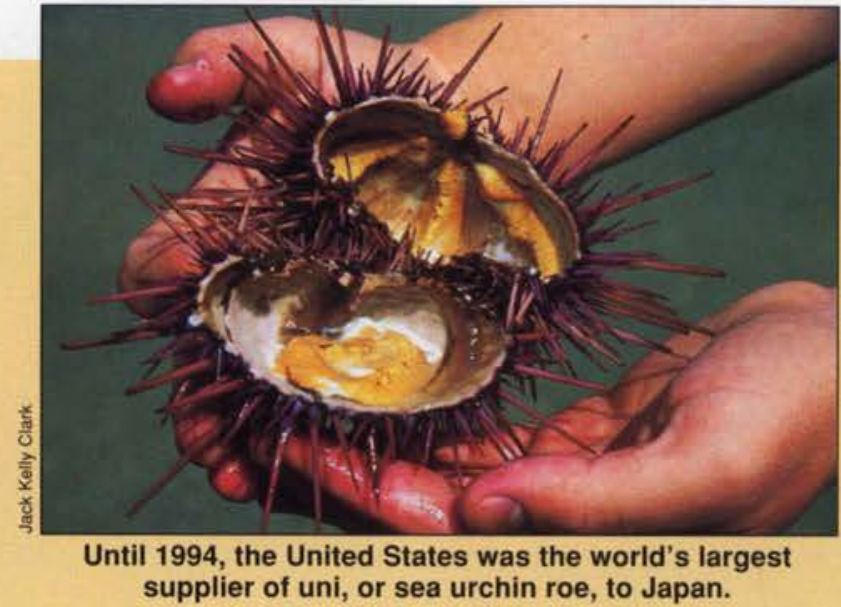

\title{
Aquaculture boosts urchin roe production
}

\section{Susan McBride}

Red sea urchins, with their hedgehoglike shells and five skeins of edible golden roe, are a gourmet treat, especially in Asia. Each year California divers harvest as many as $\mathbf{2 5}$ million pounds of the red sea urchins that many people find delicious and for which they are willing to pay dearly.

The commercial fishery for sea urchins in California began in the 1970s. However, the history of the sea urchin fishery dates back to the 1700 s, when sea otters, a major predator on sea urchins, were hunted nearly to extinction. With the demise of the sea otter, the sea urchin population grew unchecked.

In the 1970s, economic factors coincided to make the urchin fishery successful. Commercial air freight between the United States and Japan allowed sea urchin uni, which is consumed raw and fresh, to be flown to markets in Japan. Also, the dollar depreciated relative to the yen, making American goods, including sea urchin roe, less expensive to the Japanese (Muraoka 1990).

Sea urchins are harvested commercially worldwide, particularly in Japan, France, Chile and the United States. The United States has been the world's largest harvesting nation of sea urchins since 1988 and was the world's largest supplier of sea urchins and sea urchin roe to Japan until 1994 (Sonu 1995). However, harvests have plummeted in recent years, creating special incentives to the state's urchin divers and processors to use this valued resource efficiently.

One intriguing possibility emerged from early research, which showed that the yield of urchin roe is sensitive to food availability and may increase with preferred foods (Vadas 1977; Larson et al 1980; Lawrence et al 1997). In 1990, Sea Grant Marine Advisor Leigh Johnson demonstrated that urchins kept in seafloor enclosures could be "fattened up" if fed kelp. Gonad yield was measured as the wet weight of the gonads divided by the whole animal weight, and multiplied by 100 to give a percentage value called the "gonad index." Johnson found that over 2 months, the experimental "penned" animals had a gonad index almost double that of the controls $(16.1 \%$ vs $8.4 \%$ ) (Leighton and Johnson 1992).

These results were of great interest to the urchin industry, which had cooperated with Leigh Johnson in the studies, because selling fattened urchins in seasonal markets when supply is lowest and prices are highest would be an effective way to maximize resource value and improve market opportunities.

In response to industry requests, we initiated a series of experiments to determine whether red sea urchin could be held and fattened in culture systems on land. In addition to industry members, my collaborators include a number of professors and students at 


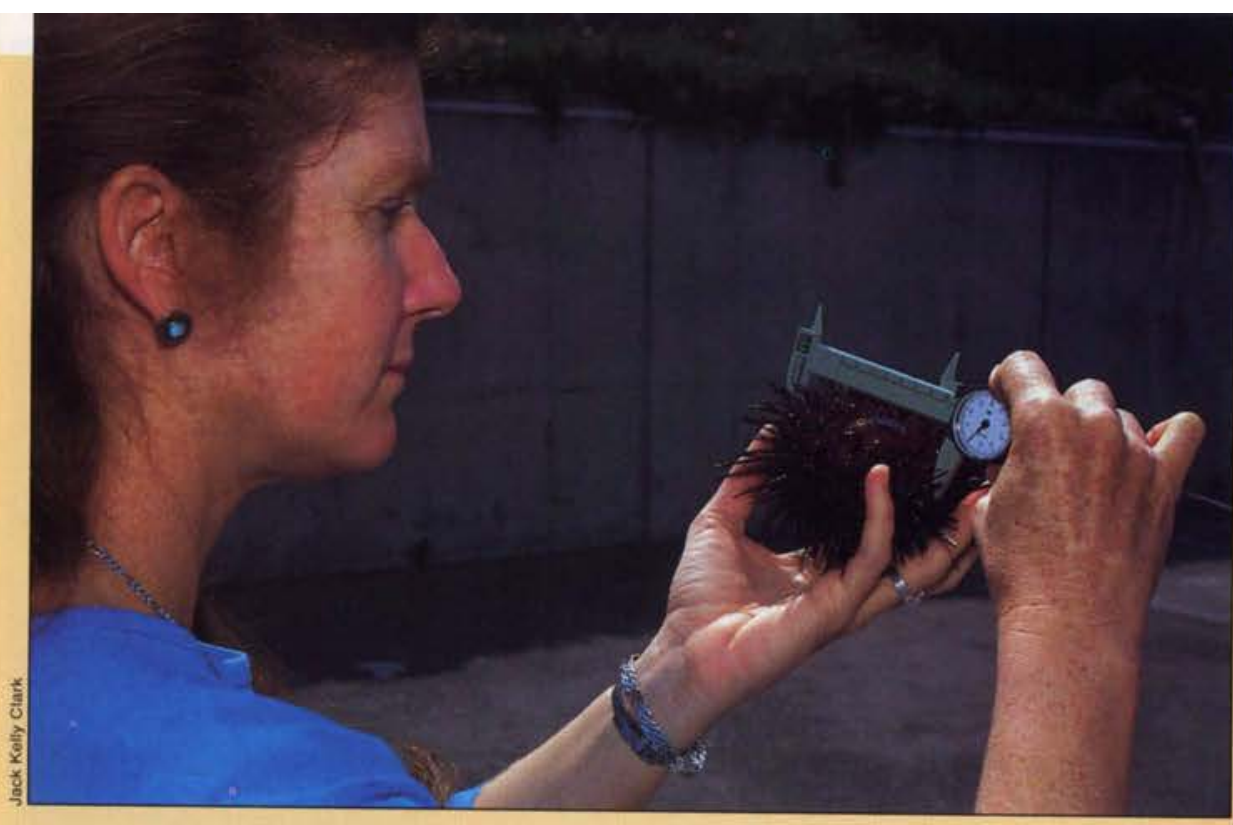

Humboldt State University (HSU) as well as the California Department of Fish and Game.

We determined that urchins could be maintained at the Telonicher Marine Laboratory at HSU and that the urchin gonad index increased about $1 \%$ per week when the urchins were fed prepared or algal diets at a range of seawater temperatures. Surprisingly, urchins fed the formulated diets consumed only about one-third as much on a dry weight basis as did the animals fed kelp. Gonad yield under all experimental conditions averaged $20 \%$ over the 15 -week experiment, well over the commercial requirement of $7 \%$ to $14 \%$ yield for processing. In all cases, food was continuously available to the urchins.

When one group of urchins was given only one-third as much prepared diet as the other, we found significant differences in amounts of feed consumed, net organic assimilation (amount of food absorbed by the gut) and gonad index. More aggressive feeding resulted in gonad indices averaging $12.2 \%$, or an increase of $1.0 \%$ compared to $0.4 \%$ per week when fed the smaller ration.

Our experiments represent only the first stage in determining the feasibility of urchin mariculture. A culturist would be able to determine the feeding rate and length of time needed to attain optimal gonad yield; if holding animals for a longer period of time was desirable, the feeding rate could be adjusted.

Aquaculture will certainly never replace the urchin fishery in our lifetime, but it may augment the harvested supply and offer alternative methods to supply urchin roe to global markets. There will be no sudden success of urchin mariculture. It will require a substantial investment of time and money such as occurred in the salmon industry, for example. More than 20 years ago, Atlantic salmon was among the highest priced and scarcest of fish, with only about 12,000 metric tons caught per year. Today more than 800,000 metric tons are harvested from net pens and the price is often below that of other harvested fish (FAO 1996).

Mariculture of urchins is conducted in Asia and is being tested in pilot programs in North America and Europe. At a recent international echinoderm conference, an entire session was centered on echinoculture. Large commercial applications of urchin mariculture are needed to show that commercially important urchins may increase gonad production outside the normal reproductive season, but those results depend on readily available and inexpensive feeds.

\section{S. McBride is Marine Advisor, Humboldt} and Mendocino counties. For more inforMcBride at (707) 443-8369. mation about this study, contact Susan

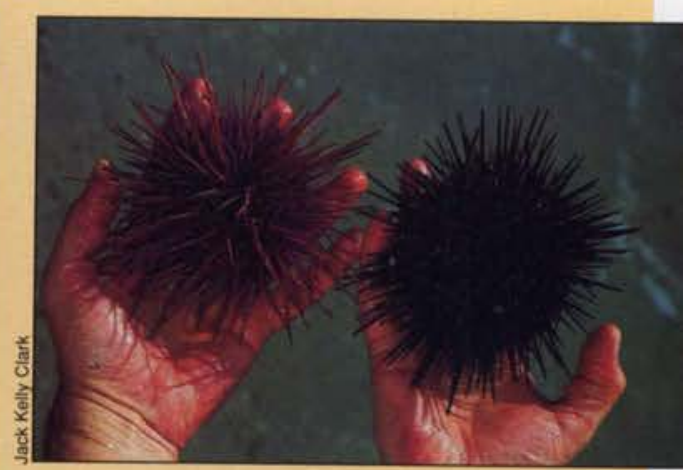

$\Delta$ The common name of the red sea urchin may be misleading, as it exhibits a variety of colors such as the lavender and dark burgundy shown.

4 Marine advisor Susan McBride measures a sea urchin. Commercially fished red sea urchins must be 3.5 inches in horizontal test diameter for legal harvest in Northern California and 3.25 inches in Southern California.

$\nabla$ Individual urchins were held in 5-gallon buckets for feeding experiments. Urchin gonad index increased about $1 \%$ per week when they were fed prepared or algal diets at a range of seawater temperatures.

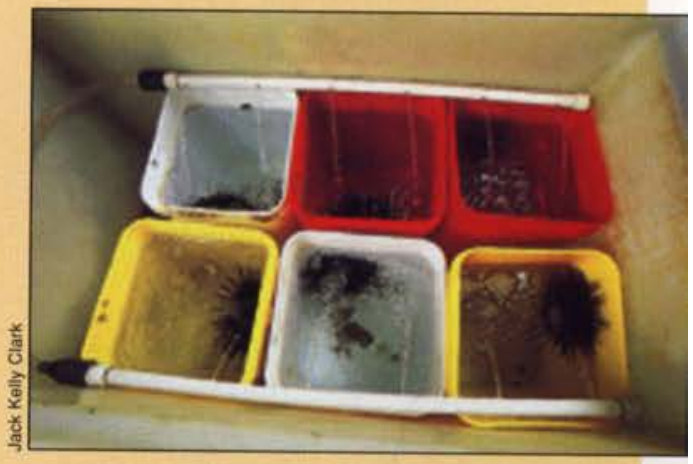

\section{References}

[FAO] Food and Agricultural Organization of the United Nations. 1996. Aquaculture Production Statistics. Fisheries Circular No. 815. Revision.

Larson BR, Vadas RL, Keser M. 1980. Feeding and nutritional ecology of the sea urchin Strongylocentrotus droebachiensis in Maine USA. Marine Biol 59:49-62.

Leighton DL, Johnson L. 1992.

Coenhancement of kelp and sea urchin resources. In: Dewees C, Davies L, (eds.). Sea urchins, abalone, and kelp: Their biology, enhancement and management. Summary of a California Sea Grant Workshop. Report No. T-CSGCP-029. 23-4.

Muraoka DD. 1990. Managing the sea urchin fishery: An economic perspective. Nat Resources J 30:139-51.

Sonu S. 1995. The Japanese sea urchin market. NOAA Technical Manuscript: NOAATM-NMFS-SWR-033. p 1-33.

Vadas R. 1977. Preferential feeding: An optimization strategy in sea urchins. Ecol Monogr 47:337-71. 